\title{
Letter to the Editor: TROSY-driven NMR backbone assignments of the 381-residue nucleotide-binding domain of the Thermus Thermophilus DnaK molecular chaperone
}

\author{
Matthew Revington ${ }^{\mathrm{a}}$ \& Erik R.P. Zuiderweg ${ }^{\mathrm{a}, \mathrm{b}, \mathrm{c}, *}$ \\ ${ }^{\mathrm{a}}$ Biophysics Research Division and Departments of ${ }^{\mathrm{b}}$ Biological Chemistry and ${ }^{\mathrm{c}}$ Chemistry, University of \\ Michigan, 930 N. University Ave., Ann Arbor, MI 48109-1055, U.S.A.
}

Received 5 May 2004; Accepted 20 May 2004

Key words: chemical shift index, Hsp70, large protein, sequential assignment, thermophile, Trosy-triple resonance

\section{Biological context}

Highly homologous Hsp70 (70 kDa Heat shock protein) chaperones occur in prokaryotic and eukaryotic organisms. Under normal conditions Hsp70 assist in the folding and re-folding of proteins, and membrane translocation of proteins. Under stress conditions cells express Hsp70 proteins at elevated levels. The chaperone activity depends on the binding of exposed hydrophobic sequences of unfolded proteins in a hydrophobic pocket in the $25 \mathrm{kDa}$ C-terminal domain. The affinity for substrate increases several orders when ATP, bound by the $44 \mathrm{kDa} \mathrm{N}$-terminal nucleotidebinding domain (NBD), is hydrolyzed. In vivo this interdomain allosteric regulation of substrate binding is supplemented by multiple co-chaperone proteins. There is no high resolution structural data available for any complete Hsp70. Examination of crystal structures of the NBD of a mammalian Hsp70 in the ATP, ADP and AMP-PNP forms have failed to reveal significant changes, leaving the basis of the allosteric mechanism in question (Flaherty et al., 1994).

Here we report the NMR backbone resonance assignment of a $44 \mathrm{kDa}$ monomeric Hsp70 NBD from the DnaK protein of the thermophilic bacteriumThermus thermophilus (Tth). No high resolution structure of any portion of Tth DnaK is available to date. However, Tth DnaK is homologous to the well-studied E. coli DnaK and bovine Hsc70 (Klostermeier et al., 1999). The backbone ${ }^{1} \mathrm{HN},{ }^{15} \mathrm{~N} \alpha,{ }^{13} \mathrm{C} \alpha$, ${ }^{13} \mathrm{C} \beta$, and ${ }^{13} \mathrm{CO}$ assignments provide, amongst others, the basis for NMR studies of the mechanism of allostery in the NBD (Revington et al., 2004).

\section{Methods and experiments}

The gene for Tth DnaK 1-381 was ligated into pET28b (Novagen, Madison, WI) resulting in the addition of a 20 residue $\mathrm{N}$-terminal sequence with a $\mathrm{His}_{6}$ tag and a thrombin cleavage site. E. coli strain BL21(DE3) cells with the plasmid were grown at $37{ }^{\circ} \mathrm{C}$ in $\mathrm{M} 9$ media with $99 \%{ }^{2} \mathrm{H}_{2} 0,98 \%{ }^{15} \mathrm{NH}_{4} \mathrm{Cl}$, and $99 \%{ }^{13} \mathrm{C},{ }^{1} \mathrm{H}$ glucose (Cambridge Isotope Laboratories, Andover, MA). Tth DnaK was unfolded in $6 \mathrm{M}$ guanidine- $\mathrm{HCl}$ at $80{ }^{\circ} \mathrm{C}$, loaded on a $\mathrm{Ni}^{2+}$-NTA agarose column (Qiagen, Valencia, CA) and eluted with an imidazole gradient. TROSY spectra (Pervushin et al., 1996) confirmed that the protein was properly re-folded.

NMR spectra were collected at $55{ }^{\circ} \mathrm{C}$ on an $800 \mathrm{MHz}$ Varian Inova spectrometer. Samples were about $400 \mu \mathrm{M}$ DnaK in $50 \mathrm{mM}$ Hepes pH 7.4, $10 \mathrm{mM}$ $\mathrm{KCl}, 5 \mathrm{mM} \mathrm{MgCl} 2,5 \mathrm{mM} \mathrm{ADP}$ and $5 \mathrm{mM} \mathrm{Na}_{2} \mathrm{PO}_{4}$. At these conditions, the protein has a rotational correlation time of about $20 \mathrm{~ns}$. 3D $\mathrm{HNCA}, \mathrm{HN}(\mathrm{CO}) \mathrm{CA}$, $\mathrm{HNCO}, \mathrm{HN}(\mathrm{CA}) \mathrm{CO}, \mathrm{HNCACB}, \mathrm{HN}(\mathrm{CO}) \mathrm{CACB}$ and 3D ${ }^{15} \mathrm{~N}$-resolved NOESY spectra, all optimized with TROSY (Salzmann et al, 1998) detection and ${ }^{2} \mathrm{H}$ decoupling, were collected at $\mathrm{pH}$ 7.4. The average acquisition time was $48 \mathrm{~h}$ per experiment. Additional HNCACB and HNCA spectra were collected at pH 6.0 and $55^{\circ} \mathrm{C}$. TROSY of the before and after samples of a thrombin digest confirmed that the N-terminal his-tag did not affect the structure of the protein. All spectra were processed with NMRPipe (Delaglio et al.,1995) and analyzed using XEASY (Bartels et al. 1995). 
A
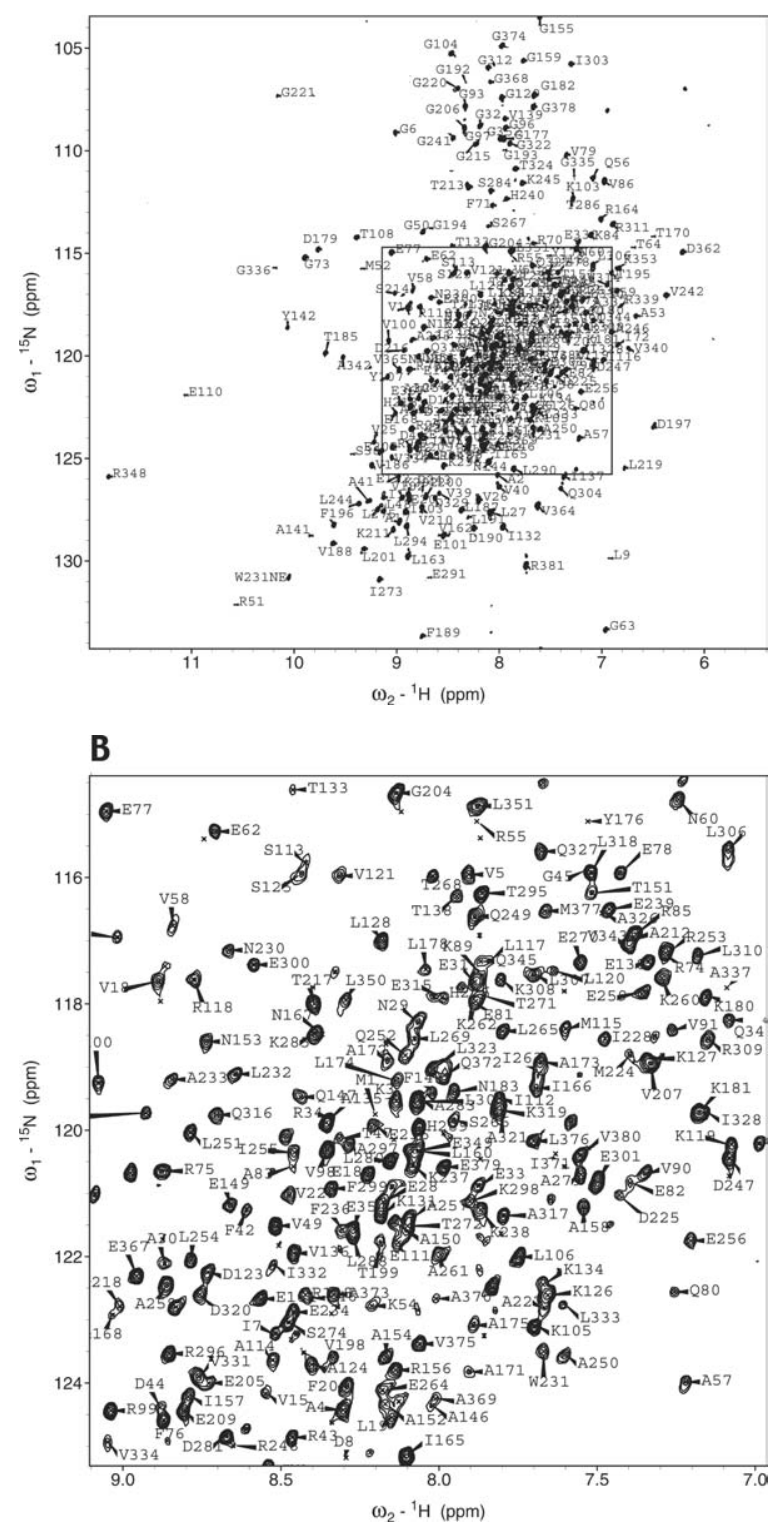

Figure 1. (A) $800 \mathrm{MHz}^{1} \mathrm{H}_{-}{ }^{15} \mathrm{~N}$ TROSY spectrum of ${ }^{2} \mathrm{H},{ }^{13} \mathrm{C},{ }^{15} \mathrm{~N}$ Tth DnaK NBD (residues 1-381) with assignments. (B) Enlargement of central region of $(\mathrm{A})$.

\section{Extent of assignments and data deposition}

Backbone assignments were made at $\mathrm{pH} 7.4$ for 333 of the 362 non-proline residues in the native sequence (92\%). The spectra collected at $\mathrm{pH} 6.0$ helped in the assignment of 10 surface residues whose connectivities were too weak at $\mathrm{pH} 7.4$. Only the resonances for D44 and G45 shifted significantly when the $\mathrm{pH}$ was lowered. Examination of the HNCA and HNCACB spectra indicated that D44 had undergone a reversible aspartate to isoaspartate isomerization (Tugarinov et al, 2002) at $\mathrm{pH}$ 6.0. No assignments were made for the 20 residue $\mathrm{N}$-terminal leader sequence. The unassigned non-proline residues are: G10-S14, G21K23,V35, T36, T64-K69,Y88, D95, N145, G193, F277, I278, V346, V347, N356-N360, A366 and M367. In the homologous crystal structure of Hsc70, G10-S14, I68, and G193 make contact with ligands. We hypothesize that these resonances cannot be observed due to line broadening caused by dynamical processes. The secondary structure was calculated based on the $\mathrm{C} \alpha, \mathrm{C} \beta$ and $\mathrm{C}^{\prime}$ chemical shifts using the CSI program (Wishart and Sykes, 1994). All predicted secondary structure elements aligned with the secondary structure observed in the crystal structure of bovine Hsc70, except for a $\beta$-strand between residues 196 and 204 and an $\alpha$-helix, between residues 342 and 348 . This may indicate local deviations from the crystal structure or a-typical chemical shifts due to ligand contacts in these regions. The chemical shifts have been deposited in the BioMagResBank (accession number 6229).

\section{Acknowledgements}

We thank Dr J. Reinstein (Max-Planck-Institute for Molecular Physiology) for a plasmid of TTh DnaK, and Dr Y. Zhang for general discussions. We thank Dr A. Kurochkin for the maintenance of the spectrometers, and the Keck Foundation, NIH, NSF and Michigan Life Sciences Corridor for funds for NMR spectrometers. The work was supported by NIH grant R01 GM63027.

\section{References}

Bartels, C., Xia T., Billeter, M., Güntert, P. and Wüthrich, K. (1995) J. Biomol. NMR, 6, 1-10.

Delaglio, F., Grzesiek, S., Vuister, G.W., Zhu, G., Pfeifer, J. and Bax, A. (1995) J. Biomol. NMR., 6, 277-293.

Flaherty, K.M., Wilbanks, S.M., DeLuca-Flaherty, C. and McKay, D.B. (1994) J. Biol. Chem., 269, 12899-12907.

Klostermeier, D., Seidel, R. and Reinstein, J. (1999) J. Mol. Biol., 287, 511-525.

Pervushin, K., Riek, R., Wider, G. and Wüthrich, K. (1996) Proc. Natl. Acad. Sci. USA, 94, 12366-12371.

Revington, M., Holder, T.M. and Zuiderweg, E.R.P. (2004) J. Biol. Chem., 279, 33958-33967.

Salzmann, M., Pervushin, K., Wider, G., Senn, H. and Wüthrich, K. (1998) Proc. Natl. Acad. Sci. USA, 95, 13585-13590.

Tugarinov, V., Muhandiram, R., Ayed, A. and Kay, L.E. (2002) J. Am. Chem. Soc., 124, 10025-10035.

Wishart, D.S. and Sykes, B.D. (1994) J. Biomol. NMR, 4, 171-180. 